\title{
The Application of Plant Landscape in Interior Design
}

\author{
Jinjin Wang \\ Institute of environmental art .Hebei Institute of Fine Art ,ShiJiaZhuang,HeBei, 050700, China
}

Keywords: Plant landscape; Interior design; The research status; The application form

\begin{abstract}
On the basis of important role for plant landscape in the modern interior design, analysis in-depth of the current research status of plant landscape in the indoor design and the main application form, so that the plant landscape in interior design can be more widely promotion and application, provide higher quality of life for more people with good living environment.
\end{abstract}

\section{Introduction}

The purpose of interior design not only is a decoration and beautification of the interface, more important is according to the different requirements of indoor space reconstruction space, namely the unreasonable interior space reconstruction to be practical, comfortable space. The most important means is to separate the interior space design. Adopts what kind of separation method, should according to the requirements of its space characteristics and function, but also take into account the artistic characteristics and psychological factors, the separation methods to meet different requirements, on the basis of creating aesthetic feeling, appeal and artistic conception.

Building and continues today, with the development of human beings is one of the material conditions of people live. Construction in addition to the factors such as the adornment of the appearance and construction details, and the most important things, is through the construction entity to surround close space - space. Space is the most important content, is the embodiment of the architectural function, is the soul of the building. In the past a period of interior space design, designers tend to focus on three major indoor interface the decoration and beautiful, and ignore the use of interior space function. After long time practice and cognition, people gradually realized the purpose of interior design, is not only the decoration and beautification of interface and more importantly, the use function of interior space. As the emphasis of the Bauhaus school "form follows function", advocated abandoning false on the surface of the decoration, the rationality of create space function.

Some architectural interior space can meet the needs of people to function, but there are also many public building interior space and improved interior space, can't satisfy people's needs directly. Reengineering space, it is based on the original building space form of space, to meet people in work and life to the different needs of space function. Separation method mainly has three categories, one is through the physical space, change the size of the specific space, shape; The second is the virtual space, through the material, color, lighting, etc on the impact of psychological; Three is a free space, by using levels of disjunctive space, furniture and decorations. These three methods can be used alone in the design practice and can be used in comprehensive.

As people living standard enhancement and the pursuit of a higher quality of life, more and more is also high to the requirement of interior design, the people have not only stay on to meet the basic physiological needs, and pay more attention to indoor design value of the psychological needs and cultural level. Will plant landscape in be being designed indoors, fusion and use, can add vitality and vigor for blunt interior space, and can make people and plants landscape, intimate contact. Integrated into the plant landscape in the interior design has become a new needs and fashion, representing the future development direction of interior design.

\section{The Origin of Indoor Greening Design}

Indoor greening has a long history. With the development of urban and suburban construction, green space. People has a natural nostalgia for the lost green space. Especially living and working in the 
multi-story or high-rise building room around within the people, the more eager to have a green environment. Plants in the case of light can make the air fresh, also can adjust the humidity, plant green is a kind of downy color, can give the stimulation of the cerebral cortex to good, Can make the fatigue of the nervous system after intense work and think relaxes and recovery; Flowers plant with its full, more various and beautify the indoor environment, add interest, give a person with beautiful enjoyment. Indoor afforest is part of the interior design, and interior design closely linked. Mainly using plant materials combined with the interior of the shape, size, use garden commonly used gimmick, organization, perfect, beautification, downy occupied space, coordinator of the relationship with the environment.

\section{The Content of the Indoor Greening Design}

The Function of Indoor Greening Design and Function. On the one hand the greening design can beautify the indoor environment. Landscaping in indoor environment beautification function mainly has two aspects: one is the beauty of the plant itself, including its color, shape and fragrant; it is through the plant combined with indoor environment properly, organically configuration, from the aspects of color, shape, texture, etc to produce bright contrast, to form a beautiful environment.

On the other hand, it can purify indoor air and adjust microclimate. Modern science has proved that greening has quite important ecological function. Good indoor greening can purify indoor air, adjust the indoor temperature and humidity, beneficial to human body health; Plants absorb carbon dioxide during photosynthesis to evaporation, release oxygen, some plants can absorb the harmful gas, secretion and sexual material, kill the bacteria in the air. The outside wall was lush branches can keep out sunshine, have the effect of shading and regulate indoor temperature. According to the measured, building on the west wall planting parthenocissus tricuspidata, in vegetation cover $90 \%$ of the cases, outer wall surface temperature can reduce $8.2{ }^{\circ} \mathrm{C}$ [1].

Secondly, edify sentiment, cultivation of body and mind. Most of the time is spent in indoor, indoor environment closed and drab, can make people lose the closeness to nature. Human instinct of nature have a strong yearning. This desire can be done by indoor afforest, because the plant is a product of nature, the most can represent the nature. Indoor greening design, introduce the nature flowers and plants indoors, make the person as if place oneself in nature, so as to achieve loosen body and mind, maintain mental health. In addition, people in the indoor virescence maintenance and management of the process also can edify sentiment, cultivation of body and mind.

Indoor Greening Design of Plant Selection and Display. Light is the main factors that affect plant growth and development, indoor greening plants to consider the choice of suitable for plant growth and normal need to light, temperature and humidity; Plant size corresponds to a size, different size of space to choose a different dimension of plant material; Plant morphology, texture, colour wants to be coordinated with the purpose of the room, such as the study configuration such as asparagus, orchids, can make the space appears elegant and quiet.

The display of indoor greening design plants: indoor greening plants to choose appropriate container design, USES the appropriate way of display, plus the lamplight illuminate, etc. Indoor greening design plants container: indoor greening design of plant cultivation of container is divided into ordinary planting basin, basin and planting groove three types.

Way of Indoor Greening Design of Display. Indoor greening design plants generally can take the display as follows: on the floor (suitable for larger potted plants, especially the form, structure of plants); Furniture or windowsill (suitable for relatively small potted, because only put them at a certain height, can obtain good viewing Angle, thus has ideal ornamental effect); In independent type base (suitable for a long, drooping leaf plants. In order to coordinate with the style of interior decoration, can choose pseudo-classic style base (such as root base), or concise form vertical gypsum base, glass fiber reinforced plastic imitation plaster base; hanging from the ceiling (suitable for branches drooping plants, such as bracket plant, bird's nest ferns. Suspension can make drooping branches grow shine, and the most easy to attract the line of sight of people, special effects); suspended on the wall (suitable for trailing plants and small flowering plants. Trailing plants are 
commonly used to draw the outline of the window profile, flowering plants with its gorgeous colors and the metope of quietly elegant contrast).

A lighting on the one hand can improve plant light conditions, promote plant growth (type fluorescent lamp is suitable for use sun); On the other hand can create a special atmosphere (appropriate use spotlight or floodlight) at night. Lighting the way into the projection lighting, lighting and back lighting up. Upward lighting way is to put the lights in plants, the main purpose is the special effect of shadow on the wall; Back lighting is hidden behind the plants, the lights make the plant under the condition of the backlight produces dark outline, exquisitely carved effect [2].

Different Greening of Bedroom Space Layout. Dr. D.G Hess yon decoration household plants can be divided into six regions, according to statistics, $79 \%$ of households put plants in the living room, $51 \%$ of households put plants in the kitchen, $34 \%$ of households put plants in the porch of the gate and the stair well, $28 \%$ of households put plants in restaurants, $12 \%$ of households put plants in the bathroom, $11 \%$ of households put plants in the bedroom. According to the author's observation, ordinary Chinese afforest decorate the space order of priority is: the bedroom of the balcony, sitting room, dining-room, bedroom.

The sitting room green: the sitting room living room is the main place, daily living space is relatively large, so the afforestation of the sitting room decorate should become the focus of the bedroom is green. Single function the display of the main of the sitting room is sofa, chairs, tea tables, TV, acoustics, etc. To afforest decorate should pay attention to the quantity, variety shoulds not be too much. A bigger space of the sitting room, can be placed at the entrance of flower arrangement, miniascape, greeter effect; Can be placed two basin is relatively tall araucaria in the middle of the sitting room, cycads, to break up a space; Corner cabinet can be placed, the window beside the bamboo of curvature of the spinal column, rubber tree, bamboo, etc. Multi-function hall to both the role of the sitting room, dining-room and even study, its main position usually arrange sofa, talking with tea table of center again. Can put potted flower by sofa, tea table on flower arranging, corner can decorate a large potted plants such as rubber tree and the other, can also be used to break up a space, plants were isolated talks, dine, learning space, etc. Plants do not centered, with slightly on one side is preferred. Pay attention to the rich space level as far as possible, small plants can be put in mesa, large plants on the ground and the vertical plant suspension. In addition, the plant should also pay attention to color texture and indoor tonal collocation. If the environment is tonal, dense tonal should be treated by some plants.

Balcony greening and windowsill: balcony of type opening open that is a good rest and looking place, with strong area through reasonable afforest decorate can make the person as if place oneself in the natural environment; If combined with cage and water cluster cases, the effect is more ideal. Decoration area is smaller through different kinds of medium and small potted, or in the roof hanging plant, also can create good landscape effects. Window it is a good place for arrangement of greening, hanging greening plants on the window sill, can soften the monotonous rigid construction line, make its show alive and vibrant. If set on the window sill planting groove, groove colourful four seasons of flowers and plants and small shrubs, the effect is more ideal. An important part of balcony afforest, promote appetite, harmonious relationship.

Table of plant design: the design should not be multifarious, concise, a bottle of flower arrangement.

Bedroom green: bedroom should create a quiet, sweet, leisure and comfortable atmosphere, relatively capacious bedroom can use standing type large pot; Hanging potted small bedroom can choose, or plants on the fine set of basin after put on the dresser or windowsill.

\section{Indoor Greening Design Way}

Way of indoor greening design in addition to depending on the materials of the plant morphology, size, color and ecological habits, but also on the basis of the size of interior space, the strength of the light and the seasonal change, and the atmosphere. Its design methods and various forms, including display, clings to type, suspension type, wall hung, plant type, and the design of the miniature foliage plant greening. 
Display Greening Design. Display is the most common indoor greening design and the most common way of design, including point, line, and the type 3 kinds. Of which point is the most common, the potted plant on the desktop, tea table, GuiJiao, windowsill, and a corner, or in the indoor air suspension, a green viewpoint. Line and the chip is a group of potted plant is put into a line or organized into freestyle, rules of flake graphics, rise to organize interior space, to distinguish the different USES place indoors, or combined with furniture, have the effect of dividing range.

Type Greening Design. Halls and restaurants, such as indoor areas need to split, with belt clings to plant quarantine, or the fence with a bar or design decorative pattern to provide clings to plants and clings to coordinate in shape, color, material, etc. In order to make reasonable interior space division, coordination, and practical.

Suspension Hanging Greening Design. Large indoor space, combined with the ceiling, lamps and lanterns. Put it beside the window, the corner, the furniture has a certain volume of Yin hanging plants, improve the indoor artificial buildings as dry as a chip and drab feeling caused by the hard line, build a lively space stereo aesthetic feeling, make full use of space.

Wall Greening Design. The beautification of greening indoor wall, also is popular among people. Wall hanging wall hanging method, hang a wall trying to, recessed method and window method. Advance on the wall set up local uneven hole wall and wall, for placed potted plants; Or flowers is placed in the ground, or planting groove, build by laying bricks or stones and then grows on plants, make its growth along the wall, form indoor local green space; Or on the wall to set up support, in the case of do not take up the place flowerpot, to enrich the space.

Plant Type Greening Design. This design method is used for indoor garden and indoor large hall has sufficient space. Planting, use more natural type, namely the plane dependent accumulation and dispersion, density, and shrubs and herbs and cover plant level, and the harmonious collocation of style, color, proper attention to use the color of indoor foliage plants to enrich the landscape image; Consider with rocks, combination of waterscape, landscape into at the same time, the simulation of nature landscape [3].

Indoor greening design is the modern interior design in the direction of sustainable development. With the improving gradually of people's living standard, the further awakening consciousness of ecological environment, indoor greening design will be one of the indispensable important component of modern indoor design.

\section{Plant Landscape in the Important Role of Interior Design}

Purify Air, Adjust the Indoor Micro Climate. Plants have many physiological function, reasonable application in interior design can give full play to its ecological effect, adjust indoor micro climate. Plants which can be used as indoor "natural oxygen bar", increase the oxygen content of indoor through photosynthesis, and can be a "natural" humidifier indoor, increase indoor through transpiration

Humidity. Plants can absorb the harmful substances in the environment through or through its volatile substances inhibiting bacteria in the air, purify the air. NASA scientists have done the experiment, to explore the plants for indoor air purification effect, the results show that indoor plants can effectively reduce the air of chloroform, benzene, formaldehyde and other harmful trace gas concentration.

Beautify the Environment, the Diffusion Space. Plant landscape beautification indoor environment is mainly reflected in two aspects. First is the vitality of plants landscape manifested itself and natural beauty. In use in the interior design of the landscape plants generally have higher ornamental, its vitality and different plant landscape unique shape, color and fragrance is a reflection of its aesthetic feeling. Second, plants can and other indoor decoration by reasonable combination and organic collocation, constitute a unified whole, color and form from the aspects such as combination of aesthetic feeling. Modern architectural interior space for more angular geometry, give a person curt indifference. And through the vivid projection of plant landscape and gentle appeal, was blunt interior space will become kind and pleasant.

Edify Sentiment, Cultivate One's Morality. Plant landscape is the product of nature, its biggest 
characteristic is to have vitality. Plant landscape, through the power of its thriving and inspire people to love nature, love life. Growing exuberant plants can also make people refreshed, full of vitality, and some of the thicket, horizontal extension longitudinal stretch plants give a person with strong will, show the praise of life [4]. People in ablaze during rest or work, can to water plants, maintenance, etc., this itself is also a way to edify sentiment, cultivate one's morality raises a gender.

\section{Plant Landscape of the Current Research Situation of Interior Design}

Application of the Principles of Plant Landscape in Interior Design. The modern interior design mainly includes the space, decoration, furnishings, color, lighting and greening in six aspects, and greening is need the collocation of plant landscape to reflect, it play an important role in the interior design. To give full play to the role of the green, we should follow the following three basic principles.

Economic and practical, pay attention to demand: the application of plant landscape of the first principle of interior design is the starting from the actual needs, choose different plants according to the different nature of interior space. Mostly used to meet the guests, such as sitting room, can put guest-greeting pine bonsai or miniascape, etc., to build a warm and cheerful welcome atmosphere. And the place of the study is mainly used to learn the job, can put some elegant and pure and fresh green plants. At the same time, the selection principle of plant landscape should also pay attention to the economy. The collocation of plant landscape to adapted to different indoor decoration style and the grade, make indoor "soft decoration" and "hard decorate" coordinated.

Placement is appropriate, rational layout, plant landscape in indoor put suitable to interior space, not abrupt occupy most of the interior space, also cannot humble put inside corner, let a person feel its existence. Put the plant landscape of value should not only embody the beautification, and can't interfere with the normal activities of people indoors. We must keep the stability of large plants put at the same time, to ensure safety. Between different plant landscape layout reasonable, not indoor and other decorative conflict. Plant landscape put in indoor appropriate and reasonable layout should not only conform to the laws of art, artistic beauty, and to demonstrate its unique vitality, reveal natural charm.

According to the common size of interior space and the proportion of plant landscape gives some reference standard [5], in order to make plant landscape and the indoor environment more harmonious.

Suitable brightness and color phase modulation: the feeling of people of color is very sensitive, so should mainly consider to use contrast methods in interior design highlights the importance of plant landscape and stereo feeling. Warm environment should mainly choose slants cool color plants, like sitting room background for light or bright color, can consider to choose dark green foliage plants or colored flowers; And the environment that cool color moves should mainly choose slant warm color plants, such as toilet or bedroom generally insufficient light, dark environment, can consider to choose yellowish-white flowers, etc. So, can obtain ideal foil effect by comparison.

The Deduction of Houseplant Landscape Design Technique. Different indoor design different deductive methods are needed to show, at present about the deduction of houseplant landscape design gimmick basically has two kinds: point, line and plane layout and comprehensive type layout.

Point, line and plane layout: Abstract art pioneer, Russian painter and art theorist, vasily kandinsky, once said "depends on the individual spirit in art, this kind of element analysis is the bridge to work intrinsic rhythm, main performance for each of these elements in the art form dot, line, face". In the modern interior design, application of plant landscape design period of commonly used layout can be divided into point layout, plane layout and line layout. "On the geometry, is a kind of invisible entity, so it is defined as a nonphysical existence. From the material content, points equal to zero. From her appearance, some practical applications, its own is marked with practical purpose factors. Used point belongs to the daily environment of sound, it quietly". Point of application in interior design, landscape plant layout, usually put plants in the center of the indoor 
area, mostly independent and tall trees or shrubs, to strengthen interior space level. "Line is applied to all kinds of art, the essence of it is more or less accurately in artistic ways to translate. In geometry, line is an invisible entity, it is a point in the moving track, so it is produced by the movement, has a tendency to stretches infinitely". Used in interior design line layout and plant landscape, is refers to the plants arranged in a straight line or curve, can effective segmentation of interior space, so organization interior streamline. "From the point of view of geometry, surface is the line movement track and as a result, is the symbol of balanced line equality. Noodles are the result of the development of point and line and they performance, the background of the illumination characteristics of both tolerant, gentle and full of the milk of human kindness". Yu Zhongting plant landscape of plane layout more application, such as the lobby area larger interior space, can be varied. Can according to different colour, also can undertake collocation according to different forms.

Comprehensive layout: plant landscape in comprehensive type layout in interior design is to point layout and line layout and comprehensive application of the layout, its different combinations can produce different effect. In the atrium, the space is larger interior design such as the lobby, mainly using the integrated type layout. According to the design requirements of different location, different shape, different color, different height of plants are combined, the overall landscape looked like, one integrated mass. Can also consider groundcover plants, herbs, trees and shrubs are combined, highlight the different levels and focus on different color, texture coordinate, at the same time can be combined with rockery, water features, constitute a natural landscape. The essence of comprehensive type layout is prominent in the overall coordinated local contrast, so as to display the strewn at random have the dimensional administrative levels and absorbing design effect.

\section{The Application Status of Plant Landscape in Interior Design}

The Methods of Plant Landscape Design in Interior Design. Main application of plant landscape in interior design according to different plant morphology, size, color, ecological habit and the light of different space, size, such as atmosphere needs to be determined. Different plant landscape in be being designed indoors can have different application forms.

About the application of plant landscape in interior design forms, specifically the main can be divided into the following kinds.

Display: display the most common and most commonly used for the interior design of the configuration forms, mainly through the foregoing interpretation technique of dot, line and layout to reflect. Put miniascape in indoor desk, tea table and window, can constitute a point of plant landscape. To a linear combination of different plants or surface type combination, to combine with other interior decoration, can have different effects.

Wall: wall-mounted plant landscape design also was deeply loved by people, the main form of hanging wall hanging, hanging wall managed to, recessed method and window method. This kind of configuration is mainly used in space larger interior space, have higher walls or decoration. Can choose clings to plant, or in the metope of different height setting wall of the hole, put miniascape, also can stick wall put stents, by placing a variety of small flowers form a unified whole. The brandy hercules winery has one side wall of plant landscape in the wall, very grand.

Indoor combination cultivation and mini garden: through accumulation and dispersion dependency, looked like the collocation of composite applications to a variety of plant landscape, but also cooperate with rockery, water features indoor mini garden, it is also a large form is commonly used in interior design in recent years. Both can foil the atmosphere of interior design, and can give full play to the ecological effect of the combination of a variety of plants, is a kind of extremely potential force and development of plant landscape configuration form. In gardening developed in the Netherlands, will this combination potted is called "living garden, moving sculpture", more image highlights its ornamental value.

Different Interior Space in Different Plant Landscape Application Forms. Different places have different environment, give play to different functions, so should "adjust measures to local conditions", according to the different place different plant landscape configuration. 
Hotel atrium or lobby: a growing number of hotels, office buildings and so on began to pay attention to the interior design of the lobby, because its main used to welcome guests, need to create a warm atmosphere. Can put some air plants, such as dispersion and or the other, marla barney, Africa jasmine, etc., and the lobby desk or rest area can put prosperous tower, such as powder, poinsettia, etc. In addition, still should according to the different locations in the lobby and choose different plants, such as facing the place can put air, plants, have a nice message can be rich tree, araucaria [8], or cycads, decoration, can also be symmetry or with some other ferns or seasonal flowers foil decoration alone. And in the place such as pillars or stairs guardrail, can decorate some vine plants, climbing or drooping, it can add some lively light elegant.

Office: office is the main indoor environment, the modern people to work in the office appropriate to raise some flowers and plants, can have the effect of air conditioning, not only can adjust people's state of mind, alleviate the monotony of work and tired. Aloe vera, bracketplant, mother-in-law is a natural scavenger, can remove harmful substances in the air. Aloe vera can strong absorption of indoor formaldehyde. Ivy, cycas, chrysanthemum, can effectively remove sulfur dioxide, chlorine, ethyl ether, ethylene, carbon monoxide, nitrogen peroxide and other pests. Orchid, osmanthus, wintersweet is a natural dust collector, the cilia can intercept and sluggish particles floating in the air and soot. And cloves, jasmine, rose, violet and mint plants can make people relaxed, spirit is happy, is conducive to sleep, also can improve the work efficiency.

The choice of household plants: family environment is an important place in daily life, should be based on different household space of the application of plant landscape. Sitting room as the main place of reception guests and family activities, plant landscape option is given priority to with simple, beautiful, generous, can choose India rubber trees, coconut and so on, and also can put a few small bonsai appropriately on the table. The bedroom is the main place to rest, have illicit close sex, plant landscape mainly to adorn action. Can choose a small flowers such as hitom, geranium. The study serves as read, study, should be mainly put green plants, reduce fatigue. Relatively damp bathroom environment, can put hygrophilous cold water flowers or cockscomb, etc.

Daily Maintenance and Management of the Indoor Plants Landscape. To ensure the ornamental plant landscape, you must first make sure it could be normal growth, so should pay attention to the oxidation and the daily management of plants. First should choose suitable cultivation matrix, choose according to different plants ready river sand, rural soil, sawdust, perlite and other different medium. Secondly in the routine maintenance should be timely watering, fertilizing, ensure that plant growth is rapid, vibrant. Again, the foliage plants also should pay attention to trim regularly, maintain its shape. In addition, still should pay attention to prevention and control of plant diseases and insect pests.

Anyhow, plant landscape came from nature, by its unique form and color and natural beauty of the show and can construct the elegant indoor environment, has been applied in the modern interior design more and more widely. Reasonable use of plant landscape in interior design can make people more close to nature, blend in nature.

Using ground or metope material changes in the form of virtual space, widely used in interior design. Such as residential interior design, in a porch place that take the door, usually use stone or tile floor. Because this is the place where people really change clothes in shoes. Porch is the ground of wear-resisting, and easy to clean up than in other places. The sofa of the sitting room before placing a carpet, make people not only their feet up feel comfortable, also produced a remarkable times feeling is sweet the coexistence of space. Some high-end beauty salon, glass on the floor to the operating room, under the glass is colorful rubble, and hit the lights, exquisitely carved, and create a wonderful effect of the pursuit of beauty, charm of metaphor and beauty, and elsewhere in the stone material ground form contrast.

Metope material can also cause the simple sense of the space effect. Bar often use metope material difference, the division of regional performance services and consumption. In the business hall, a wall in the simulation of the decorative stone art, arrangement of greening plants according to the wall, make indoor produced an area full of natural taste, also add the cultural implication. Chinese restaurant of one side wall design for the jiangnan style of a beautiful window as opposed 
to a storefront window, in the person produce psychological modern history with a blend of two kinds of space. Of course, when we use different materials for space reconstruction, should fully understand the basic features of all kinds of material, can skillfully use it. One of the basic materials of wood as a building, its material is qualitative light, natural grain is beautiful, visual and touch the warmth, have very good elasticity and toughness, and easy processing, for electricity, heat has very good insulation. But the downside is soft in texture, not wear-resisting, so often and stone collocation is used. Two kinds of stone material is divided into natural stone and artificial stone. We often use in interior design is the granite and marble. Using natural marble, very beautiful, but in less than a year, the ground was been east to west, refute. This is mainly because the marble belongs to metamorphic rock, fine, color variety, there are beautiful natural color, but it is the biggest drawback is not wear-resisting, easy to weathering, so only suitable for indoor metope act the role of material. Granite belongs to magmatic rocks. The characteristics of compact structure, high hardness, wear resistance, pressure, refractory and atmospheric chemical corrosion resistance. Have the laudatory title of "stone rotten to be one thousand". More to the ground and inside and outside wall act the role of brick. The disadvantage is that color pattern. It seems that when we choose stone, must certainly grasp the characteristics of it clearly.

Use transparent glass as the material of disjunctive space, can produce the dimensional feeling of a kind of bricks. The biggest difference between glass and other building materials are transparent, at the same time, the glass, and the function of sound insulation and heat preservation. With glass interior space separation materials, has a unique effect. Some modern company's conference room with glass walls, not only ensure the meeting undisturbed, and shows the company's openness and transparency of the decision-making. Modern shopping malls with glass in the one horn of the sales hall separated the rest area, enables customers to temporarily avoid the busy shopping area to enjoy a moment of quiet, also to communicate and shopping area, good produce continue consumption desire. In glass disjunctive space, has the characteristics of internal and external space is connected fully integrated.

\section{References}

[1]Chen Song. 100 kinds of healthy indoor plants [M]. Harbin publishing house. 2008

[2]Lai fengwen. Interior design principle [M]. China building industry press. 2006

[3]Li Lairong. Indoor foliage and decoration [M]. China forestry publishing house

[4]Li qing. Modern afforest adornment of the bedroom [J]. China's health issue. 1996

[5]Li Xiao. Indoor layout and configuration [M]. Background of science and technology news, 2000 